\title{
The Assessment of Climate Change and Watershed Effect on the Heterotrophic Metabolism in the Lake Onego Ecosystem
}

\author{
Nataliia Kalinkina ${ }^{1}$, Larisa Nazarova ${ }^{1}$, Elena Tekanova ${ }^{1}$, Peter Litinsky ${ }^{2}$, \\ Anastasiia Sidorova ${ }^{1}$ \\ ${ }^{I}$ Northern Water Problems Institute KarRC RAS \\ ${ }^{2}$ Forest Institute KarRC RAS
}

\begin{abstract}
Lake Onego, as one of the largest water bodies in a humid zone, is the recipient of terrestrial carbon and plays an important role in the global balance of this element. Due to heterotrophic metabolism in the Lake Onego ecosystem, substantial emissions of carbon dioxide from this lake into the atmosphere can be assumed. However, the extent of this phenomenon is still poorly known. As a climate change has led to an increase in water and organic matter flow into the northern water bodies, the carbon balance study of aquatic ecosystems is of particular relevance. The elements of the water balance for the Lake Onego catchment area in the current climate conditions are assessed. Based on satellite images the model of Lake Onego watershed terrestrial ecosystems is used to simulate the flow of organic matter into the lake with different types of vegetation and topography consideration. The assessment of the benthic communities habitat is carried out taking into account the accumulation of organic matter in various parts of Lake Onego.
\end{abstract}

Keywords: Lake Onego, remote sensing of watershed state, climate change, deepwater benthos.

\section{INTRODUCTION}

Lake Onego is one of the two greatest lakes in north-west region of Russia. It is cold and deep. The characteristics of the lake according to Atlas "Lake Onego" [1] are as follows: surface area $-9720 \mathrm{~km}^{2}$; average depth - $30 \mathrm{~m}$; maximum depth - $120 \mathrm{~m}$; volume of water - $295 \mathrm{~km}^{3}$; drainage basin area $53100 \mathrm{~km}^{2}$. There are 152 tributaries of Lake Onego. The lake is characterized by a high heterogeneity. Its main part maintains oligotrophic conditions and high quality of water. Two north-western bays (Petrozavodskaya and Kondopozskaya Bays) are polluted by municipal and industrial waste waters of the towns (Petrozavodsk, Kondopoga and Medvezhyegorsk) and characterized by mesotrophic status. The surface areas of these bays make up about $4 \%$ of the lake.

In recent years, a profound transformation of Lake Onego ecosystem is observed. The reduction of deepwater benthos number is recorded in the different regions of the lake [2]. In general, this indicates the reoligotrophisation processes that occur in many reservoirs in the world. However, plankton indicators suggest return of the lakes to the lower trophic status $[3,4,5]$. In Lake Onego the state of plankton communities remains relatively stable [6], while benthos community undergoes dramatic changes.

It is necessary to consider the peculiarities of the ecosystem metabolism to understand the complex processes in the Lake Onego. The ratio of primary production and respiration are indicators of organic matter balance and anthropogenic impact on the water body [7, 8]. It is important to know the amount of organic matter inflowing from the catchment area. This is particularly relevant in relation to climate change, which became the most prominent in the 2000s [9]. The aim of the present study was to analyze the Lake Onego ecosystem transformation, with due regard to the ecosystems metabolism, the impact of the catchment area, and climate change effect.

\section{MATERIALS AND METHODS}

The data of long-term meteorological observations on Hydrometeorology and Environmental Monitoring Stations of Russian Federal Service network for the period up to 2016 were used for the analysis and evaluation of the variability of the climate characteristics (air temperature).

Phytoplankton photosynthesis was measured using radiocarbon [10] and plankton respiration rate was determined using the light/dark bottle method to detect changes in the oxygen concentration in the sample water [11] after incubation at a temperature corresponding to lake water.

The deepwater benthos in Lake Onego was sampled by dredge with square area $0.025 \mathrm{~m}^{2}$ according to Guidelines [12, 13]. 
DOC export to the lake is estimated as a function of the vegetation cover types within the watershed. Watershed delineation were made using $30 \mathrm{~m}$ resolution DEM, vegetation types is a result of Landsat TM/ETM+ imagery classification. Images and DEMs were downloaded from GLCF ftp://ftp.glcf.umd.edu/glcf/Landsat/WRS2

Another approach to information extraction from TM/ETM+ imagery has been applied. It involves transformation of multi-dimensional image space in visible $3 \mathrm{D}$ one and localization in this space the segments of main ecosystem types of territory. So, the method can be named "spectral space modeling". Spectral space model is built in LC1-LC2-MSI axis: two first principal components of the image matrix in logarithmic form, and Moisture Stress Index:

$\mathrm{LC} 1=0.2793 * \ln (\mathrm{R})+0.7786^{*}-\ln (\mathrm{NIR})+0.5619 * \ln (\mathrm{SWIR} 2)$

$\mathrm{LC} 2=0.5887 * \ln (\mathrm{R})-0.6012 * \ln (\mathrm{NIR})+0.5404 * \ln (\mathrm{SWIR} 2)$

$\mathrm{MSI}=\mathrm{SWIR} 1 / \mathrm{NIR}$

where R, NIR, SWIR1, SWIR2 - Landsat ETM+ bands $3,4,5,7$ digital numbers, respectively; ln natural logarithm.

LC1 accounts for general scene brightness, LC2 correlate with quantity of green biomass, but not orthogonal to brightness $[14,15]$. So, in physical terms this transformation is similar to Tasseled Cap $[16,17]$, but it makes space more "compact", understandable and suitable for analyzing. Localization of spectral classes within the model space was made using airphotos, forest inventory maps, landscape transects and other ground knowledge.

\section{RESULTS AND DISCUSSION}

The last decade there is a sharp decrease of the deepwater benthos number in different areas of Lake Onego. These processes are the most significant in Petrozavodskaya Bay. The total abundance and biomass of benthos at the central station of this bay fell by 6 times in 2010-2016 compared with 19901995 (Table 1).

Table I

The abundance and biomass of the deepwater benthos in Petrozavodskaya Bay of Lake Onego in the 1990-2016 (the central

\begin{tabular}{|l|l|c|c|}
\hline \multirow{4}{*}{ Years } & Parameters & $\begin{array}{c}\text { Total abundance. } \\
\text { thousands of ind } / \mathrm{m}^{2}\end{array}$ & $\begin{array}{c}\text { Total } \\
\text { biomass, } \mathrm{g} / \mathrm{m}^{2}\end{array}$ \\
\hline \multirow{3}{*}{$\begin{array}{l}1990- \\
1995\end{array}$} & Average & 6.47 & 15.26 \\
\cline { 2 - 4 } & min & 6.13 & 10.63 \\
\hline \multirow{3}{*}{$\begin{array}{l}1996- \\
2000\end{array}$} & Average & 7.14 & 20.95 \\
\cline { 2 - 4 } & min & 4.66 & 9.80 \\
\hline \multirow{3}{*}{$\begin{array}{l}2001- \\
2005\end{array}$} & Average & 3.69 & 8.56 \\
\cline { 2 - 4 } & min & 5.73 & 11.73 \\
\hline \multirow{3}{*}{$\begin{array}{l}2006- \\
2010\end{array}$} & Average & 4.92 & 18.20 \\
\cline { 2 - 4 } & min & 4.39 & 14.52 \\
\cline { 2 - 4 } & $\max$ & 5.37 & 25.82 \\
\hline \multirow{3}{*}{$\begin{array}{l}2011- \\
2016\end{array}$} & Average & 2.99 & 6.93 \\
\cline { 2 - 4 } & $\min$ & 1.22 & 3.86 \\
\cline { 2 - 4 } & $\max$ & 5.22 & 11.00 \\
\hline
\end{tabular}

The main representatives of the benthos are relic crustaceans (Amphipoda), oligochaetes and chironomids. The abundance and biomass of amphipods and oligochaetes reduced during the analyzed period. Parameters of chironomids, which are characterized by low share in the total number and biomass, do not show any tendency to change. Integrated assessment of the benthos total biomass at depths of 10-30 $\mathrm{m}$ was done for Petrozavodskaya Bay in different periods of observation. In 2001-2006 total integral biomass of benthos (in terms of organic carbon) at depths of $10-30 \mathrm{~m}$ was 524 tons [18]. In 2007-2014 the integral biomass at these depths was 283 tons i.e. it has decreased almost in 2 times [2].

The production and respiration processes in Lake Onega [7] were taken into account to explain the observed situation with a sharp change in the benthic abundance. There is a dramatic difference in the rate of photosynthesis and destruction of organic matter in polluted bays and the central part of the Lake Onego due to the high heterogeneity of the ecosystem. The processes of anthropogenic eutrophication are observed in the north-western bays of Lake Onego (Petrozavodskaya and Kondopozskaya bays). Here there are the maximum values of primary production, especially in the upper parts of the bays: $327 \pm 57 \mathrm{mg}$ $\mathrm{C} / \mathrm{M}^{3}$.day in the surface layer in Kondopozskaya Bay; $127 \pm 27 \mathrm{mg} \mathrm{C} / \mathrm{M}^{3}$.day in the surface layer in Petrozavodskaya Bay. The values of respiration in these bays are also high: $170 \pm 77$ и $103 \pm 21 \mathrm{mg}$ $\mathrm{C} / \mathrm{M}^{3} \cdot$ day in this layer, respectively.

The situation at the deepwater areas of Lake Onego quite differs from the polluted bays. The primary production of organic matter and respiration rates at the central part of lake are characterized by low values. The average values of photosynthesis for profundal lake area is $19.7 \pm 1.8 \mathrm{mg} \mathrm{C} / \mathrm{m}^{3} \cdot$ day. The intensity of respiration processes in the central parts of the lake is characterized by values $31.0 \pm 4.6 \mathrm{mg}$ $\mathrm{C} / \mathrm{M}^{3}$.day. Rates of photosynthesis and destruction are comparable with that of extracellular phytoplankton production. So, all organic matter synthesized during photosynthesis is mineralized in the photic zone.

The integral values of primary production and respiration (in terms of water column) are very different. The respiration rates are higher than production ones 10-12 times. A significant predominance of respiration above the primary production is connected with the heterotrophic type of metabolism of Lake Onego ecosystem due to a large number of allochthonous organic matter which inflow into the reservoir.

Since all of the synthesized (autochthonous) organic matter potentially can be exploited in the surface layers of water, the food base of deepwater benthos of Lake Onego is mainly determined by allochthonous organic matter. The main source of allochthonous organic carbon entering the Lake Onega is the river flow (90-91.5\%) due to the high 
swamped catchment [20]. A small part of the allochthonous organic carbon enters the lake from the precipitation (3.9-5\%) and wastewaters (4.6-5\%).

It was of interest to review the dynamics of the carbon inflow with the tributaries in the context of the sharp decline of benthos abundance in Lake Onego. The results of observations on the tributaries of Lake Onego during 1965-2008 were used [19]. In 19651986 permanent seasonal observations were carried out on 22 lake tributaries and occasionally at several small rivers. In the 2000 s, the monitoring was conducted on 28 tributaries. It was shown that some changes in the organic carbon flows into the lake occurred (Table 2). Thus, the years 2007-2008 were characterized by increased river discharge into the lake. At the same period the total organic carbon concentrations in the water of the main tributaries increased: up 13.4-16.1 $\mathrm{mgC} / 1$ (1985-2002) to 16.8$18.1 \mathrm{mgC} / 1$ (2007-2008). These factors together can determine the increase in organic carbon input with the river waters in 2007-2008 to 1.4-1.6 times as compared to the previous period.

Table II

River discharge into the Lake Onego (V, km3/year) and total organic carbon inflow with the tributaries (TOC, thousands of tons/year) in 1965-2008 (according to the data by [20])

\begin{tabular}{|l|c|c|c|c|}
\hline Parameters & $\begin{array}{c}1965- \\
1966\end{array}$ & $\begin{array}{c}1985- \\
1986\end{array}$ & $\begin{array}{c}2001- \\
2002\end{array}$ & $\begin{array}{c}2007- \\
2008\end{array}$ \\
\hline V & 15.55 & 12.75 & 14 & 17.79 \\
\hline TOC & 216 & 189 & 214 & $299^{*}$ \\
\hline
\end{tabular}

Note: * - including, 36.7 thousands of tons/year - flow of total organic carbon in previously unstudied tributaries.

However, the accuracy of the organic carbon inflow estimates depends on the completeness of the studied tributaries (see Table 2). In this regard, the organic carbon flow from the catchment area was assessed using satellite images.

Spectral segments of mature and old-growth pine (Pinus sylvestris L.) forests, dominated in the region, are straightening from ecological optimum (moraine ridges - myrtillus type) in directions of two main environment gradients:

a) automorphic - lack of water and nutrition (fluvioglacial sands -> bedrock)

b) hydromorphic - degree of paludification (lacustrian planes)

Thus, the biogeocenotic complexes (Quaternary deposits - soil - vegetation) are identified. Clearly traced in spectral space succession trajectories of forest regeneration (new clear-cut - young - middle age - sub-climax), also associated with the type of Quaternary deposits.

For mire ecosystems spectral classes accurately reflect type of water and mineral nutrition (oligotrophic/mesotrophic). Ambiguous classes (e.g. some types of non-closed canopy stands) decomposition made with use of geomorphometric model and time series imagery, and as a result all basic classes of primary ecosystems, and also various variants and stages of their natural and anthropogenous disturbances, in total a few dozen categories are distinguished (Fig. 1).

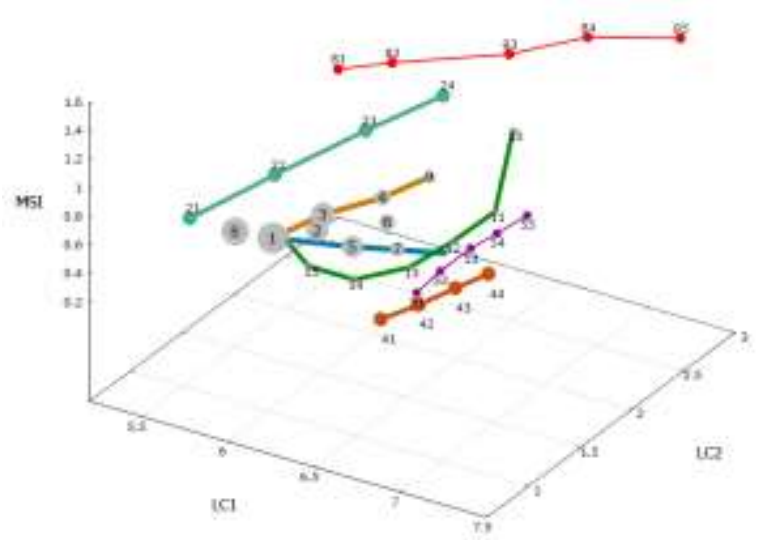

Fig. 1. Spectral space model of the watershed terrstrial ecosystems. Digits represent the centers of spectral classes: 1-2-3-4 - pine forests on authomorfic soils (upland), 8 - spruce forest, 5-6-7 wetland forests, 21-24 - open mesotrophic mires, 41-44 - open ombrotrophic mires, 10-15 - trajectory of forest regeneration, 5155 - crops, meadows, 81-85 - non-vegetation (sands, roads, settlements).

At present no in situ data within the Onego lake basin is available, thus the values of DOC export from each type of ecosystem could only be assessed from literature data [21, 22]. Mean values for two main ecosystem classes, upland forests and wetlands, were accepted (Table 3 ).

Table III

Total watershed loading to the Onego lake

\begin{tabular}{|c|c|c|c|c|}
\hline $\begin{array}{c}\text { Ecosystem } \\
\text { type }\end{array}$ & $\begin{array}{c}\text { Spectral } \\
\text { classes } \\
\text { (see Fig. 1) }\end{array}$ & $\begin{array}{c}\text { Total } \\
\text { area, } \\
\mathrm{mln} \text { ha }\end{array}$ & $\begin{array}{c}\text { DOC } \\
\text { export, } \\
\mathrm{ha}^{-1} \cdot \mathrm{yr}^{-1}\end{array}$ & $\begin{array}{c}\text { Lake input, } \\
\text { thousand } \\
\text { of ton } \cdot \mathrm{yr}^{-1}\end{array}$ \\
\hline $\begin{array}{c}\text { upland } \\
\text { forest }\end{array}$ & $\begin{array}{c}1-4,8,12- \\
15\end{array}$ & 3.8 & 40 & 152 \\
\hline peatland & $\begin{array}{c}5-7,21-24, \\
41-44\end{array}$ & 0.87 & 70 & 60.9 \\
\hline & & & Total & 212.9 \\
\hline
\end{tabular}

This approximate estimate shows that about 200 thousand of tons of dissolved organic carbon inflow from the catchment area into Lake Onego in the 1990-2010 per year. This value is sufficiently close to those obtained previously, despite the fact that total organic carbon flow was accounted in the field observations (see Table 2). Thus, it can be argued that the flow of organic carbon from the tributaries into Lake Onego in the 2000s (when there was a change in the benthic communities), at least not decreased. Consequently, the decline of the deepwater benthos abundance in Lake Onego is not connected with the organic carbon inflow from the tributaries.

A possible reason of benthos abundance decreasing at the bottom is the reduction of anthropogenic load in the last 15 years [2]. The wastewaters inflow in Petrozavodskaya Bay in 19902005 was 46-51 million of $\mathrm{m}^{3}$ per year. Since the year 2005, the anthropogenic load on the Petrozavodskaya 
bay is 28-33 million of $\mathrm{m}^{3}$ per year, i.e. it is reduced in 1.5-1.8 times. However, the scale of reduction in benthos abundance (at the central station in Petrozavodskaya Bay - 6 times) are not comparable with the lowering of the wastewater volume.

It should be noted that the most important group of deepwater benthic communities are relic crustaceans, i.e. coldwater organisms. For glacial relic crustaceans optimal temperature ranges are shifted toward lower values [23]. This explains their distribution in reservoirs with greater depths, where the water temperature is kept low in the summer.
Perhaps the reason for reduction of benthos abundance, including glacial relict crustaceans, is a climate change. The air temperature data indicate climate change in Karelia. So, for the period from 1989 to present time, the average annual temperature has increased by $1-2{ }^{\circ} \mathrm{C}$ as compared to with the previous period [9]. The duration of the ice-free period for Lake Onego increased by 20 days [24].

The average annual air temperature in Petrozavodsk can be presented in terms of deviations from the climatic norm, see Figure 2.

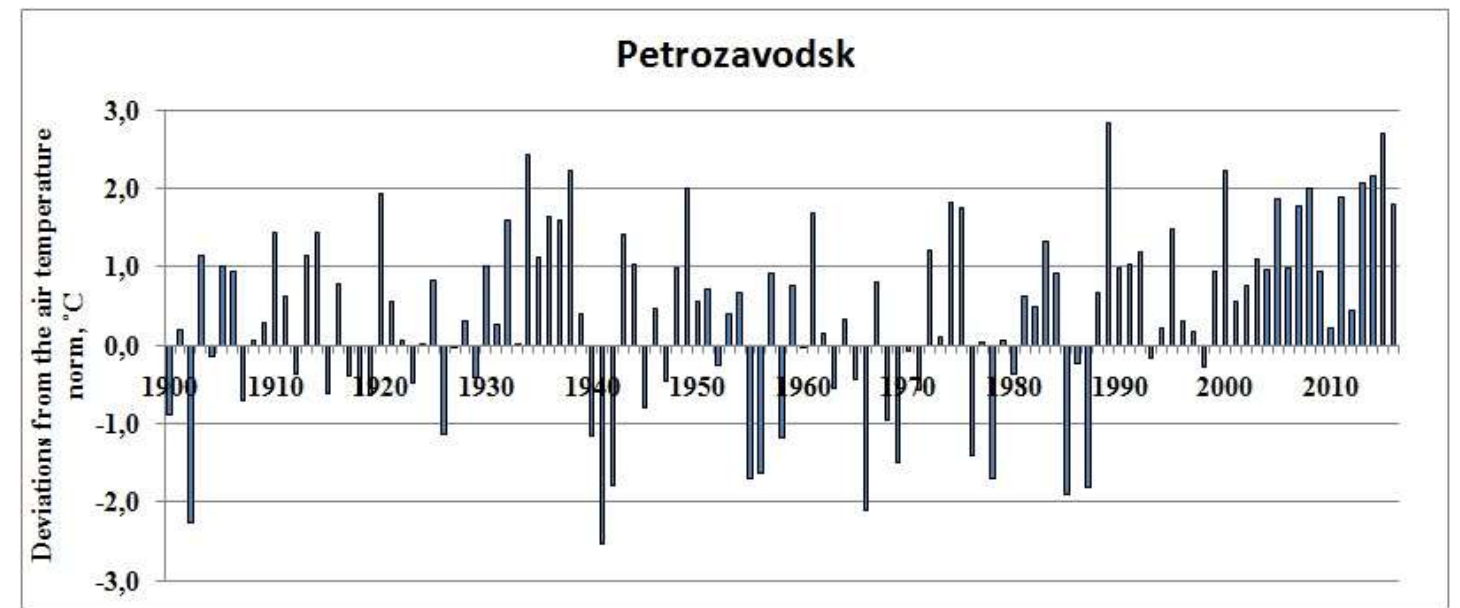

Fig. 2. The deviations of the average annual air temperature $\left({ }^{\circ} \mathrm{C}\right)$ from the climatic norm (1961-1990), Meteorological station, Petrozavodsk, 1900-2016.

The long-term average annual air temperatures for the 1961-1990 were used as the climate norm. The graph shows the temperature increase since the beginning of the century. In the 1950s the relative cooling was observed, which was replaced in the 1980 s by the climate warming. Since 1989, a steady increase of average annual air temperature above normal ones is observed. This trend is also observed for the entire territory of the Republic of Karelia [9, $25,26]$. It should be noted that, although the temperature during the last 20 years exceeds the climatic norm, its further growth is not revealed.

Currently the change of the surface water layer temperature of Lake Onego is studied. It is shown that the shift of water surface temperature through $10^{\circ} \mathrm{C}$ occurs on earlier date of spring with the rate 1.4-1.7 days/10 years [27]. It is found that the amount of effective for biota water temperatures (above $10^{\circ} \mathrm{C}$ ) increased and the period of "biological summer" became longer as a result of regional climate change over the Lake Onego. However, data on the changes of temperature in the deep layers of the water is absent. The observed reaction of the deepwater benthos determines the relevance of a more detailed investigation of possible temperature regime changes for Lake Onego under conditions of regional climate change.

\section{IV.CONCLUSIONS}

Thus, the heterotrophic metabolism of the Lake Onego ecosystem shows the great role of allochthonous organic matter in the functioning of deepwater benthic communities. The field observation of the organic carbon inflow into Lake Onego and assessment of terrestrial organic carbon fluxes based on the analysis of satellite images have shown that the amount of allochthonous organic matter remains relatively constant throughout the 2000s. Possible reasons for a sharp decline of deepwater benthos abundance in Lake Onego in the last decade may be a reduction of anthropogenic load and climate change.

\section{ACKNOWLEDGMENTS}

The part $(50 \%)$ of the study has been financially supported by the Russian Science Foundation (№1417-00766).

\section{REFERENCES}

[1] Lake Onego. Atlas / Editor. Ed. N. N. Filatov. Petrozavodsk: Karelian Research Centre, 2010. (In Russian)

[2] N. Kalinkina, A. Sidorova, T. Polyakova, N. Belkina, N. Berezina, I. Litvinova, Decline in the deepwater benthic communities abundance in the Onego Lake under multifactor influence // Principy èkologii. 2016. Vol. 5. № 2. pp. 47-68. (In Russian)

[3] M. M. Tilzer, U. Gaedke, A. Schweizer, B. Beese, T. Wiese, Interannual variability of phytoplankton productivity and related parameters in Lake Constance: no response to 
decreased phosphorus loading? // Journal of Plankton Research. 1991.Vol. 13. N. 4. pp. 755-777.

[4] D. Straile and W. Geller, Crustacean zooplankton in Lake Constance from 1920 to 1995: Response to eutrophication and re-oligotrophication // Advances in Limnology. 1998. V. 53. pp. 255-274.

[5] E.V. Donk, D.O. Hessen, A.M. Verschoor, R.D. Gulati, Reoligotrophication by phosphorus reduction and effects on seston qualityin lakes // Limnologica. 2008. V. 38. pp. 189 202.

[6] E. V. Tekanova and M. T. Syarki, Peculiarities of phenology of the primary production process in the pelagic zone of Lake Onega // Biology Bulletin. 2015, Volume 42, Issue 6, pp. 556-562.

[7] Tekanova E.V. and Timakova T.M., Primary production and destruction of organic matter in Lake Onego // Status and Problems of Production Hydrobiology. Moscow, 2006. pp. 60-70. (In Russian)

[8] E.V. Tekanova, The contribution of primary production to organic carbon content in Lake Onego // Inland water biology. Vol. 5, Issue 4, pp. 328-332.

[9] L. E. Nazarova, Variability of average long-term air temperature values in Karelia // Regional Research of Russia. 2014. T. 146, issuance 4. pp. 39-45. (In Russian)

[10] S. I. Kuznetsov and G. A. Dubinina, Methods of studying aquatic organisms / Nauka, Moscow, 1989 (in Russian).

[11] G. G. Winberg, Primary production of water bodies // Science Academy of BSSR, Minsk 1960 (in Russian).

[12] Guidelines for the collection and processing of materials in hydrobiological research on freshwater reservoirs. Zoobenthos and its products / Ed. G.G. Winberg, G.M. Lavrentiev. - L .: GosNIORKh. 1984. 52 p. (In Russian)

[13] Guidelines for the collection and processing of materials in the conduct of monitoring of biological pollution in the Gulf of Finland. / Ed. A. Alimov, T. Florinskaya (eds), St. Petersburg, 2005 (In Russian)

[14] P. Yu. Litinskiy, Multispectral imagery classification method based on spectral space modeling // Proceedings of the Karelian Research Centre of the Russian Academy of Sciences. № 5. Mathematical Modeling and Information Technologies. 2011. pp. 45-54. (In Russian)

[15] P. Yu. Litinskiy, Geoinformation model of Eastern Fennoscandia Northern taiga ecosystems // Proceedings of the Karelian Research Centre of the Russian Academy of Sciences. № 1. BIOGEOGRAPHY Series. 2012. pp. 3-15. (In Russian)

[16] R .J. Kauth and G. S. Thomas, The Tasseled Cap - a graphic description of the spectral-temporal development of agricultural crops as seen by Landsat // Proceedings on the Symposium on Machine Processing of Remotely Sensed Data, 4b: 41-51, 6 June - 2 July 1976 (West Lafayette, Indiana: LARS, Purdue University)
[17] C. Huang, Yang, L. Wylie, Collin Homer, G. Zylstra, Derivation of a tasselled cap transformation based on Landsat 7 at-satellite reflectance. USGS Staff - Published Research. 2002. Paper 621. Conservation Ecology 8 (2): 3.

[18] A.V. Ryabinkin and T. N. Polyakova, Macrozoobenthos of lake and its role in fish food // Bioresource of Lake Onego. Petrozavodsk: Karelian Research Centre, 2008. pp. 67-91. (In Russian)

[19] A. V. Sabylina, External load on the lake // The largest lakereservoirs of the North-West European part of Russia: current state and change of ecosystems under climatic and anthropogenic impacts / Editor. Ed. N. N. Filatov. Petrozavodsk: Karelian Research Centre, 2015. pp. 68-72. (In Russian)

[20] A. V. Sabylina, Organic carbon, total phosphorus and total nitrogen inflow to Lake Onego with stream runoff, and their removal by Svir river waters in 1965-2008 // Proceedings of the Karelian Research Centre of the Russian Academy of Sciences. LIMNOLOGY Series. № 9, 2016. pp. 68-77. (In Russian)

[21] C. D. Canham, M. L. Pace, M. J. Papaik, A. G. B. Primack, K. M. Roy, R. J. Maranger, R. P. Curran, D. M. Spada, $A$ spatially explicit watershed-scale analysis of dissolved organic carbon in Adirondack lakes// Ecological applications, 14: 2004 pp. 839-854.

[22] H. A. De Wit, J. L. J. Ledesma, M. N. Futter, Aquatic DOC export from subarctic Atlantic blanket bog in Norway is controlled by seasalt deposition, temperature and precipitation // Biogeochemistry 2016, Volume 127, Issue 2, pp. 305-321

[23] L.M. Sushchenya, V.P. Semenchenko, V.V. Vezhnovets, Biology and production of glacial relict crustaceans /I Science and Technology, 1986. 160 p. (In Russian)

[24] T. Efremova and N. Palshin, R. Zdorovennov, Long-term characteristics of ice phenology in Karelian lakes // Estonian Journal of Earth Sciences. 2013. V. 62. № 1. pp. 33-41.

[25] L. E. Nazarova, Long-term air temperature changes in Karelia // Geography and Natural Resources. 2008. № 3. pp. 75-79. (In Russian)

[26] L. E. Nazarova, Characteristics of the dynamics of temperature of Karelia // Geography and Natural Resources. 2012, № 4. pp. 170-174. (In Russian)

[27] N.N. Filatov, L.A. Rukhovets, L.E. Nazarova, A.P. Georgiev, T.V. Ephraim, N.I. Pal'shin, Climate change impacts on the ecosystem of lake north of European Russia // Proceedings of the Russian State Hydrometeorological University. A theoretical research journal. Issue 34. -St. Petersburg: RSHU Publishers, 2014. P. 49-55. (In Russian) 